TÀl LIỆU THAM KHẢO

1. S. Jarukitsopa et al., "Epidemiology of systemic lupus erythematosus and cutaneous lupus erythematosus in a predominantly white population in the United States", Arthritis Care Res., 67(6), 2015, tr 817-828.

2. J. M. Gill, A. M. Quisel, P. V. Rocca, D. T. Walters, "Diagnosis of systemic lupus erythematosus", Am. Fam. Physician, 68(11), 2003, tr 2179-2186.

3. G. Yaniv et al., "A volcanic explosion of autoantibodies in systemic lupus erythematosus: a diversity of 180 different antibodies found in SLE patients", Autoimmun. Rev., 14(1),2015, tr 75-79.

4. M. Arroyo-Ávila et al., "Clinical associations of anti-Smith antibodies in PROFILE: a multi-ethnic lupus cohort", Clin. Rheumatol., 34(7)7,2015, tr 1217-1223.
5. Nguyễn Văn Toàn, "Áp dụng thang điểm SLEDAI trong tiên lượng bệnh nhân lupus ban đỏ hệ thống tai khoa Cấp cứu bệnh viên Bach Mai", Luânn Văn Thạc sĩ Y Học, trường Đại hơc Y Hà Nội, 2011.

6. Đăng Thu Hương, Nguyến Tất Thắng, "Tỉ lê kháng thể kháng nucleosome trong bệnh lupus ban đỏ hệ thống-Mối tương quan giữa kंháng thể kháng nucleosome với ANA, anti-dsDNA và đô hoat động của bệnh", Tap chí Y Học TP.Hồ Chí Minh, Tạp chí Y Hoc TP. Hồ Chí Minh,2013, tr 294-300.

7. Nguyễn Hữu Trường, "Nghiên cứu mối tương quan giữa mức độ hoạt động bệnh với một số tự kháng thể trong lupus ban đỏ hêe thống",Luận án Tiến sĩ Y Học, trường Đại hoc Y Hà Nội, 2017.

8. Lê Hữu Doanh, Cân Huyển Hân, "Mối liên quan giữa kháng thể kháng Smith với mức độ nặng của bênh lupus ban đỏ hệ thống", TCNCYH 98,2015, tr 3i-36.

\title{
CHỈ SỐ V3R/V7 TRONG XÁC Vİ TRÍ KHỞI PHÁT NGOÂI TÂM THU THẤT Có NGUỒN GỐC TỪ ĐƯờNG RA THẤT TRÁI VÀ ĐƯờnG RA THẤT PHẢI
}

\section{TÓM TẮT}

Đă̆t vấn đê: Vị trí khởi phát NTTT từ ĐRTT dẫn truyền điện thế về phía V3R rõ hơn và ĐRTP dẫn truyền điện thế về V7 rõ hơn. Do đó, việc sử dụng kết hợp tỷ lệ sóng $\mathrm{R}$ ở V3R và V7 có thể cải thiện sự phân biệt giữa nguî̀n gốc khởi phát ĐRTP và ĐRTT. Mục tiểu: Nhận xét giá trị chẩn đoán của chỉ số V3R/V̄7 trong dự đoán vị trí khởi phát của rối loạn nhịp thất từ đường ra thất trái và đường ra thất phải. Đối tượng \& phương pháp: 58 bệnh nhân ngoai tâm thu thất vô căn có chỉ đinh thăm dò điên sinh lý xét RFCA theo khuyến cáo của $A C C / A H A / E S C$ năm 2006, khuyến cáo của ESC năm 2015 và đồng thuận chuyên gia của EHRA/HRS năm 2009. Kết quả:Phần lớn các NTTT khởi phát ĐRTP $(74,1 \%)$, tuổi trung bình 50,5 tuổi, tỉ lệ nữ cao hơn so với nam $(69,0 \%$ so với $31,0 \%)$.Chỉ số V3R/V7 có giá tri tốt trong chẩn đoán phân biêt NTTT khởi phát ĐRTP và ĐRTT với diện tích dưới đường cong là $0,80(0,62-0,97)$. Với giá tri V3R/V7 $\geq$ 0,73; được chẩn đoán NTTT khởi phát đường ra thất trái với độ nhay $66,7 \%$ và độ đăc hiệu $100 \%$.Kết luận: Chỉ số V3R/V7 có giá trị tốt trong chẩn đoán phẩn biệt NTTT đường ra thất phải và đương ra thất trái.

Tư khóa: Ngoại tâm thu thất, đường ra thất phải, đường ra thất trái, V3R/V7.

\section{SUMMARY \\ $V_{3} R / V_{7}$ INDEX FOR DIFFERENTIATING}

${ }^{1}$ Bệnh viện Presh Ket Melea (Vương quốc Campuchia)

${ }^{2}$ Bệnh viện Bạch Mai

Chịu trách nhiệm chính: Phon Phaly

Email: drphonphaly22@gmail.com

Ngày nhận bài: 7.9.2021

Ngày phản biên khoa hoc: 25.10.2021

Ngày duyệt bài: 9.11.2021
Phon Phaly ${ }^{1}$, Trần Văn Đồng ${ }^{2}$

\section{LEFT FROM RIGHT VENTRICULAR \\ OUTFLOW TRACT ARRHYTHMIAS ORIGINS}

Background: The site of origin of ventricular arrhythmias (VAs) from the left ventricular- outflow tract (LV-OT) conducts the potential to V3R more clearly, and the RV-OT conducts the potential to V7 more clearly. Therefore, the combined use of R-wave ratios in V3R and V7 could improve the distinction between the origin of RV-OT and LV-OT. Objectives: To evaluate the diagnostic value of the V3R/V7 index in predicting the origin of ventricular arrhythmias from the LV-OT and the RV-OT. Subjects \& methods: 58 patients of idiopathic ventricular arrhythmias with indications for electrophysiological testing (RFCA) as recommended by ACC/AHA/ESC in 2006, ESC recommendations in 2015 and expert consensus by EHRA/HRS in 2009. Results: Majority of patients VAs with origin of RV-OT (74.1\%), average age is 50.5 years old, the rate of female is higher than that of male $(69.0 \%$ vs $31.0 \%)$. The V3R/V7 index has good value in the differential diagnosis of VAs with origin of RV-OT and LV-OT with the area under the curve (UAC) of 0.80 (0.62-0.97). With value V3R/V7 $\geq 0.73$; diagnosed with LV-OT with origin of left ventricular outflow tract with a sensitivity of $66.7 \%$ and a specificity of $100 \%$. Conclusion: V3R/V7 index has good value in differential diagnosis of right ventricular outflow tract and left ventricular outflow tract.

Keywords: Ventricular arrhythmias, right ventricular outflow tract, left ventricular outflow tract, V3R/V7 index.

\section{I. ĐặT VẤN ĐỀ}

Ngoại tâm thu thất (NTTT) là rối loạn nhịp tim phổ biến, bệnh gặp cả người khỏe mạnh và tăng cao ở trên những bệnh nhân có bệnh lý tim mạch ${ }^{1}$. Mối quan hệ giải phẫu giữa NTTT vị trí 
khởi phát ĐRTP và ĐRTT là yếu tố quan trọng để phân biệt nguồn gốc khởi phát NTTT. Các nghiên cứu trước đây cho thấy NTTT có nguồn gốc từ ĐRTT xuất hiện quá trình chuyển đổi sóng $R$ sớm hơn và các chỉ số được sử dụng để xác định vị trí khởi phát NTTT, đều bắt nguồn từ sự biến đổi sóng $\mathrm{R}$ ở các chuyển đao trước tim. Tuy nhiên nhiều bênh nhân cấu trúc giải phẫu thay đổi dẫn đến biến đổi tư thế tim gây những khó khăn trong phân biệt vị trí khởi phát NTTT bằng cách sử dụng các chuyển đạo trước tim tiêu chuẩn. Trên cơ Sở V3R nằm về phía bên phải nhiều hơn so với V1; V7 nằm về phía bên trái nhiều hơn so với V6 và vị trí khởi phát NTTT khởi phát ĐRTT nằm bên trái và phía sau vị trí khởi phát của NTTT khởi phát ĐRTP, gây ra sự lan truyền điện thế từ điểm khởi phát ĐRTT về phía V3R rõ hởn dẫn đến biên độ sóng $\mathrm{R}$ lớn hơn. Ngược lại, sự kích hoạt bắt nguồn từ ĐRTP phù hợp hơn với trục của chuyển đạo V7, dẫn đến biên độ sóng $R$ lớn hơn trong chuyển đạo V7. Do đó, việc sử dụng kết hợp tỷ lệ sóng $R$ ở V3R và V7 có thể cải thiện sự phân biệt giữa nguồn gốc khởi phát ĐRTP và ĐRTT.

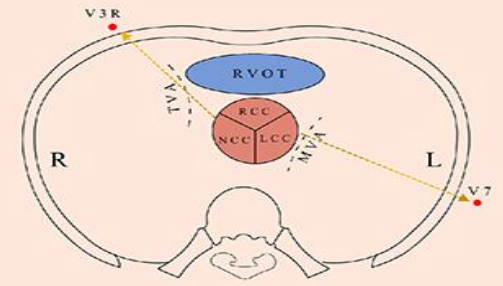

\section{Hình 1. Vị trí điểm đặt điện cực chuyển đạo $V 3 R$ và $V 7$}

Điều trị triệt đốt bằng năng lượng sóng có tần số radio là phương pháp hiệu quả đối với bệnh nhân không đáp ứng điều trị nội khoa. Tuy nhiên, để có thể điều trị thành công cần có thời gian xác định vị trí khởi phát của NTTT và điều này làm tăng nguy cơ biến chứng cho bệnh nhân cũng như ảnh hưởng không nhỏ đến bác sĩ can thiệp khi phải làm việc trong môi trường phóng xạ. Năm 2018, nghiên cứu của Dian Cheng trên 105 bệnh nhân rối loạn nhịp thất đã cho thây ý nghĩa của chỉ số V3R/V7 trong xác định ngoại tâm thu thất đường ra thất phải và trái; với chỉ số V3R/V7 $\geq 0.85$ có giá trị dự đoán ngoại tâm thu thất có nguồn gốc đường ra thất trái với độ nhay $87 \%$ và độ đăc điêu $96 \%{ }^{2}$. Mục tiêu nghiên cứu: Nhận xét giá trị chẩn đoán của chi số V3R/V7 trong dư đoán vị trí khởi phát của rối loạn nhịp thất từ đường ra thất trái và đường ra thât phải.
II. ĐỐl TƯỢNG VÀ PHƯƠNG PHÁP NGHIÊN CỨU

2.1. Đối tương nghiên cứu. Chúng tôi lựa chọn ngẫu nhiên vào nghiên cứu 58 bệnh nhẩn ngoai tâm thu thất vô căn có chỉ định thăm dò điện sinh lý xét RFCA theo khuyến cáo của ACC/AHA/ESC năm 2006, khuyến cáo của ESC năm 2015 và đồng thuận chuyên gia của EHRA/HRS năm 2009.

+ NTTT đơn dạng dày gây triệu chứng lâm sàng, không đáp ứng với điêu trị nội khoa hoặc bệnh nhân không muốn dùng thuốc kéo dài.

+ NTTT đơn dạng gây kích hoạt bão điện hoặc nhịp nhanh thất liên hồi.

+ NNT đơn dạng không bền bỉ gây triệu chứng lâm sàng, trơ hoặc không dung nạp với điều trị nội khoa.

- Các bênhh nhân được chẩn đoán xác định về vị trí ổ NTTT sau thăm dò điện sinh lý và triệt đốt thành công.

Những bệnh nhân loại trừ khỏi nghiên cứu là những bệnh nhân có ngoại tâm thu thất đa dang, có bệnh lý tim thực tổn kèm theo có thể dẫn tới biến đổi trên điện tâm đồ bề mặt: bệnh mạch vành, các bệnh lý cơ tim, bệnh lý van tim, .v.v.., có các rối loạn nhịp khác ngoài NTTT có thể làm thay đổi trục điện tim, hình dạng phức bộ QRS bình thường: block nhánh, block phân nhánh, hội chứng Brugada,.v.v.., có rối loạn nhịp thất khởi phát ở ngoài đường ra thất.

3.2. Phương pháp nghiên cứu. Nghiên cứu mô tả loạt ca bệnh được tiến hành tại viện Tim mạch, Bệnh viện Bạch Mai từ 01/08/2020 đến ngày 31/05/2021.

Tất cả bệnh nhân đủ điều kiện tham gia nghiên cứu theo tiêu chuẩn lựa chọn và tiêu chuẩn loại trừ thông qua thăm khám lâm sàng và các xét nghiệm cận lâm sàng. Ghi điên tâm đồ bề mặt với 12 chuyển đạo tiêu chuẩn và 4 chuyển đạo V3R và V7, V8, V9.

Vị trí khởi phát rối loạn nhịp thất dựa trên kết quả thăm dò điện sinh lý học và kết quảtriệt đốt, được thực hiện tại đớn vị Tim mạch can thiệp thuộc Viện Tim mạch, bệnh viện Bạch Mai.

\subsection{Các chỉ số đánh giá điện tim}

1. Biên độ sóng $R$ và $S$ trong chuyển đạo $V_{1}$ đến $V_{3}, V_{3} R$ và $V_{7}$ đến $V_{9}$.

2. Tỷ lệ sóng $V_{3} R / V_{7}$.

3. Tỷ lể sóng $V_{3} R / V_{8}$.

4. Tỷ lệ sóng $V_{3} R / V_{9}$.

5. Chỉ số vùng chuyển tiếp (TZ).

6. Tỷ lệ chuyển tiếp $V_{2}$.

7. Chỉ số $\mathrm{V}_{2} \mathrm{~S} / \mathrm{V}_{3} \mathrm{R}$.

3.4. Phân tích số liệu nghiên cứu 
- Các chỉ số được sử dụng để phân biệt NTTT khởi phát vị trí ĐRTP và ĐRTT bao gồm:

+ TZ được định nghĩa là vị trí của chuyển đạo đầu tiên trong đó biên độ sóng $R$ và $S$ bằng nhau. Điểm TZ tăng 0,5 theo vị trí của $T Z$, nếu tỷ lệ sóng $\mathrm{R} / \mathrm{S}$ nằm trong khoảng 0,9 và 1.1 .

+ Tỷ số chuyển tiếp tại $\mathrm{V} 2$ và $\mathrm{V} 3$ : tính bằng tỷ lệ giữa tỷ số biên độ $R /(R+S)$ của ngoại tâm thu và tỷ số biên độ $R /(R+S)$ nhịp xoang tại $V 2$ và $V 3$.

+ Chỉ số $V_{3} R / V_{7}$ được xác định là tỉ lệ biên độ sóng $R$ trong chuyển đạo $V_{3} R$ và $V_{7}$

+ Các chỉ số $V_{3} R / V_{8}$ và $V_{3} R / V_{9}$ được xác định tương tự.

- Phẩn tích và xử lý số liệu: Sử dụng phần mềm SPSS 22. Các biến số được phân tích giá trị trung bình $\pm S D$ và kiểm định bằng Student $T$ test. Phân tích đường cong ROC với độ chính xác được thể hiện bằng diện tích dưới đường cong (AƯC). Dùng chỉ số Youden (Youden index) J để xác định điểm cut-off và độ nhạy, độ đặc hiệu của từng điểm cut-off. Giá trị p để so sánh độ nhạy và độ đặc hiệu giữa các thuật toán khác nhau được thực hiện bằng McNemar test. Giá trị $p \leq 0,05$ được coi là có ý nghĩa thống kê.

\section{KẾT QUẢ NGHIÊN CứU}

Nghiên cứu trên 58 trường hợp NTTT, trong đó phần lớn các NTTT khởi phát ĐRTP(74,1\%). Tuổi trung bình của bệnh nhân trong nghiên cứu là 50,5 tuổi, tỉ lệ nữ cao hơn so với nam $(69,0 \%$ so với $31,0 \%)$.

4.1. Đặc điểm một số chỉ số phân biệt NTTT khởi phát đường ra thất phải và thất trái

Bảng 1. Đặc điểm môt số chỉ số phân biệt NTTT khởi phát đường ra thât phái và thât trái

\begin{tabular}{|c|c|c|c|}
\hline Thông số & $\begin{array}{c}\text { ĐRTP } \\
(n=43)\end{array}$ & $\begin{array}{c}\text { ĐRTT } \\
(n=15)\end{array}$ & $\mathbf{p}$ \\
\hline Biên độ V3R & $1,7 \pm 1,3$ & $4,7 \pm 5,1$ & 0,001 \\
\hline Biên độ V4R & $1,7 \pm 1,5$ & $6,6 \pm 12,7$ & 0,01 \\
\hline Biên độ V5R & $1,9 \pm 1,5$ & $2,7 \pm 2,5$ & 0,14 \\
\hline Biên độ V7 & $9,7 \pm 4,5$ & $6,4 \pm 4,2$ & 0,02 \\
\hline Biên độ V8 & $7,5 \pm 3,7$ & $4,9 \pm 4,9$ & 0,07 \\
\hline Biên độ V9 & $5,8 \pm 4,3$ & $2,4 \pm 2,1$ & 0,005 \\
\hline $\begin{array}{c}\text { Chỉ số biên độ } \\
\text { R/S (\%) }\end{array}$ & $33,7 \pm 31,9$ & $32,6 \pm 36,5$ & 0,88 \\
\hline Tỉ lệ V2S/V3R & 5,3 & 1,2 & 0,01 \\
\hline Tỷ lệ V3R/V7 & $0,2 \pm 0,1$ & $1,1 \pm 1,3$ & 0,00 \\
\hline Tỉ lệ V3R/V8 & $0,3 \pm 0,2$ & $2,6 \pm 5,3$ & 0,006 \\
\hline Tỷ lệ V3R/V9 & $0,4 \pm 0,4$ & $3,4 \pm 5,5$ & 0,001 \\
\hline
\end{tabular}

- Giá trị trung bình của biên độ sóng V3R và V4R cao hơn ở nhóm NTTT đường ra thất trái. Giá trị trung bình của biên độ sóng $R$ ở chuyển đạo V7 và V9 cao hơn ở nhóm ĐRTP. Tỉ lệ V3R/V7, V3R/V8,V3R/V9 trung bình ở nhóm NTTT đường ra thất phải đều cao hơn có ý nghĩa thống kê so với nhóm NTTT đường ra thất trái. Giá trị trung bình của tî lệ V2S/V3R cao hơn ở nhóm NTTT đường ra thất phải, có ý nghĩa thống kê

4.2. Giá trị chẩn đoán của chỉ số V3R/V7

Chỉ số V3R/V7 có giá trị tốt trong chẩn đoán phân biệt NTTT đường ra thất phải và đương ra thất trái với diện tích dưới đường cong là 0,80 $(0,62-0,97)$.

Dùng chỉ số Youden (Youden index) J để xác định điểm cut-off và độ nhạy, độ đặc hiệu của chỉ số V3R/V7 trong phân biệt NTTTं đường ra thất phải và thất trái, chúng tôi xác định được điểm J có giá trị V3R/V7 $\geq 0,73$; được chẩn đoán NTTT khởi phát đường ra thất trái với độ nhạy $66,7 \%$ và độ đặc hiệu $100 \%$.

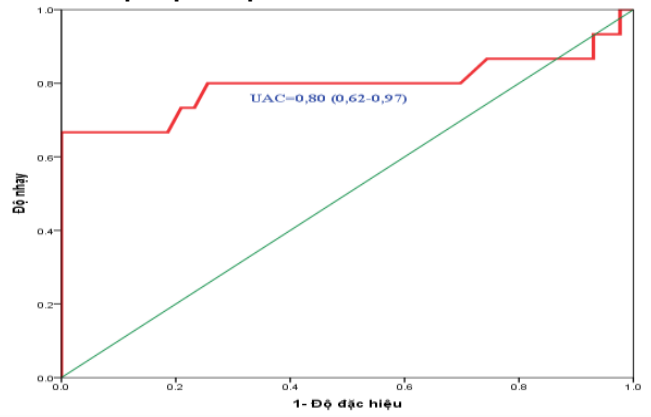

Biểu đồ 3.4. Giá trị chẩn đoán của V3R/V7 $(n=58)$

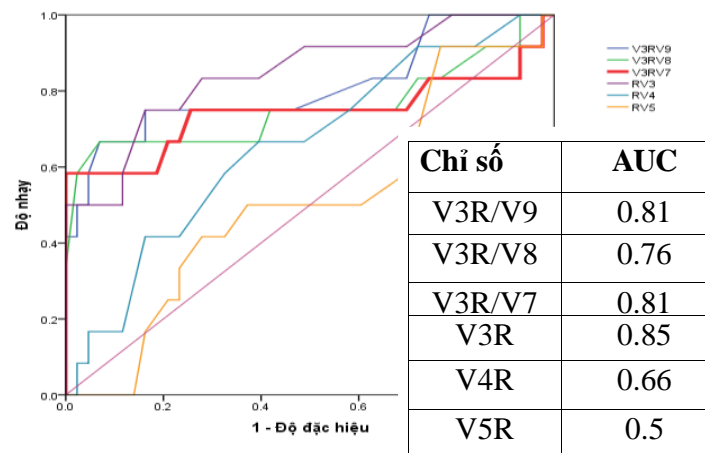

Biêu đồ 2. Giá trị chẩn đoán phân biệt NTTT đường ra thât phải và đường ra thất trái

Các chỉ số V3R/V7, V3R/V9 và biên độ sóng V3R có giá trị tốt trong chẩn đoán NTTT đường ra thất phải và thất trái. Trong đó biên độ sóng V3R có độ nhạy cao nhất $75,0 \%$ và chỉ số V3R/V7 có độ đặc hiệu cao nhất 100\%.

4.3. So sánh giá trị các tiêu chuẩn chẩn đoán phân biệt vị trí khởi phát NTTT từ ĐRTP và ĐRTT 
VIETNAM MEDICAL JOURNAL N¹ - DECEMBER - 2021

Bảng 2. So sánh giá trị chẩn đoán vị trí khởi phát NTTT từ ĐRTP và ĐRTT

\begin{tabular}{|c|c|c|c|}
\hline Tiêu chuấn & Độ nhạy (\%) & Độ đặc hiệu (\%) & AUC(95\% CI) \\
\hline TZ index $<0$ & 66,7 & 51,2 & $0,6(0,4-0,8)$ \\
\hline Chỉ số thời gian sóng $\mathrm{R} \geq 50 \%$ & 93,3 & 16,3 & $0,5(0,4-0,7)$ \\
\hline Chỉ số biên độ R/S $\geq 30 \%$ & 73,3 & 33,6 & $0,5(0,4-0,7)$ \\
\hline Chỉ số V2S/V3R $\leq 1.5$ & 76,7 & 73,3 & $0,8(0,6-0,8)$ \\
\hline Tỷ số chuyến tiếp tại V2 $\geq 0.6$ & 67,4 & 86,7 & $0,8(0,6-0,9)$ \\
\hline Tỳ lệ V4/V8 $>3$ & 81,4 & 53,7 & $0,7(0,5-0,8)$ \\
\hline Chî số V4/V8 >2.28 & 80,0 & 5,0 & $0,6(0,4-0,8)$ \\
\hline
\end{tabular}

So với chỉ số V3R/V7 các chỉ số khác dùng đế phân biệt NTTT từ ĐRTP và ĐRTT đều có độ nhạy và độ đặc hiệu thấp hơn.

\section{BÀN LUẬN}

Trong nghiên cứu này, chúng tôi sử dụng đường cong ROC để xác định giá trị chẩn đoán định khu của chỉ số V3R/V7. Kết quả nghiên cứu của chúng tôi cho thấy chỉ số V3R/V7 có giá trị tốt trong chẩn đoán phân biệt NTTT đường ra thất phải và đường ra thất trái với diện tích dưới đường cong là $0,80(0,62-0,97)$. Dùng chỉ số Youden (Youden index) J để xác định điểm cutoff và độ nhạy, độ đặc hiệu của chỉ số V3R/V7 trong phân biệt NTTT đường ra thất phải và thất trái, chúng tôi xác định được điểm J có giá trị V3R/V7 $\geq 0,73$ được chẩn đoán NTTT khởi phát ĐRTT với độ nhạy $66,7 \%$ và độ đặc hiệu $100 \%$. Kết quả này cho thấy giá trị trong chẩn đoán định khu tốt, tuy nhiên thấp hơn so với nghiên cứu nguyên bản của tác giả Dian Cheng ${ }^{3}$ năm 2018 khi cho thấy độ nhạy và độ đặc hiệu tương ứng là $80 \%$ và $98,6 \%$ khi tỉ số V3R/V7 $\geq 0,85$. Sự khác biệt này có thể do cỡ mẫu trong nghiên cứu của chúng tôi thấp hơn, đồng thời do hình thể của người Việt Nam và người nước ngoài có một số sự khác biệt nhất định dẫn đến thay đổi vị trí vùng chuyển tiếp và một vài thông số trên điê̂n tâm đồ.

Chúng tôi dùng các chỉ số được sử dụng phổ biến trong các nghiên cứu để so sánh giá trị chẩn đoán vị trí khởi phát NTTT bao gồm $\mathrm{TZ}$ index $<0$, chỉ số thời gian sóng $R \geq 50 \%$, chỉ số biên độ $R / S \geq 30 \%$, chỉ số $V 2 S / V 3 R \leq 1.5$, tỷ số chuyển tiếp tại V2 $\geq 0.6$, chỉ số V4/V8 $>2.28$. Kết quả nghiên cứu của chúng tôi cho thây các chỉ số V3R/V7, V3R/V9 và biên độ sóng V3R có giá trị tốt trong chẩn đoán NTTT đường ra thất phải và thất trái. Trong đó biên độ sóng V3R có độ nhạy cao nhất $75,0 \%$ và chỉ số V3R/V7 có độ đặc hiệu cao nhất $100 \%$. So với chỉ số V3R/V7 các chỉ số khác (TZ index, chỉ số thời gian sóng $R$, chỉ số biên độ $R / S$, chỉ số $V 2 S / V 3 R$, tỉ số chuyển tiếp tại $V 2$, tỉ lệ $V 4 / V 8$ ) dùng để phân biệt NTTT từ ĐRTP và ĐRTT đều có độ nhạy và độ đặc hiệu thấp hơn.
Chúng tôi cúng nhận thấy, giá trị của các thông số trong chẩn đoán vị trí khởi phát NTTT rất khác nhau giữa các nghiên cứu; thông thường chỉ số nào được phát triển ở nghiên cứu nào sẽ có giá trị chẩn đoán cao nhất ở nghiên cứu đó, ví dụ như chỉ số V2S/V3R ở nghiên cứu của Yoshida hay chỉ số V4/V8 trong nghiên cứu của Zhang ${ }^{4,5}$. Như vậy, để xác định giá trị chẩn đoán vị trí khởi phát NTTT từ ĐRTP hay ĐRTT cần có nhiều nghiên cứu hơn. Tuy nhiên, trong thực hành lâm sàng khó có thể loại bỏ được các yếu tố nhiễu trong quá trình thực hành, vì vậy nên sử dụng nhiều chỉ số đồng thời để có thể xác định chính xác hơn vị trí khởi phát NTTT có ĐRTP và $Đ R T T$ nhằm rút ngắn thời gian thực hiện thủ thuật và triệu đốt trong phẫu thuật. Từ đó, nâng cao chất lượng điêu trị và giảm tác hại của tia $X$ lên cả bệnh nhân và nhân viên y tế.

\section{KẾT LUÂ̂N}

Chỉ số V3R/V7 có giá trị tốt trong chẩn đoán phân biệt NTTT đường ra thất phải và đương ra thất trái. Tuy nhiên, cần có những nghiên cứu sâu hơn để so sánh giá trị của chỉ số này với các chỉ sô khác được sử dụng trước đây để xác định vị trí khởi phát NTTT.

\section{TÀI LIÊU THAM KHẢO}

1. Morshedi-Meibodi A, Evans JC, Levy D, Larson MG, Vasan RS. Clinical correlates and prognostic significance of exercise-induced ventricular premature beats in the community: the Framingham Heart Study. Circulation. 2004;109(20):2417-2422.

2. Cheng $D$, Ju $\mathbf{W}$, Zhu $L$, et al. V3R/V7 Index: $A$ Novel 'Electrocardiographic Criterion for Differentiating Left From Right Ventricular Outflow Tract Arrhythmias Origins. Circulation: Arrhythmia and Electrophysiology. 2018;11(11):e006243.

3. Cheng $D$, Ju $\mathbf{W}$, Zhu $L$, et al. VR/V7 Index. Circulation: Arrhythmia and Electrophysiology. 2018;11(11):e006243.

4. Yoshida N, Yamada T, McElderry HT, et al. A novel electrocardiographic criterion for differentiating a left from right ventricular outflow tract tachycardia origin: the V2S/V3R index. Journal of cardiovascular electrophysiology. 
2014;25(7):747-753.

5. Zhang F, Hamon D, Fang $Z$, et al. Value of a posterior electrocardiographic lead for localization of ventricular outflow tract arrhythmias: the V4/V8 ratio. JACC: Clinical Electrophysiology. 2017;3(7):678-686

\title{
ĐĂC ĐIỂM LÂM SÀNG, RỐI LOAN ĐÔNG MÁU CỦA NHIỄM KHUẨN HUYẾT SƠ SINH TAI TRUNG TÂM NHI KHOA BỆNH VIỆN TRUNG ƯO'NG THÁI NGUYÊN
}

\author{
Đỗ Thái Sơn ${ }^{1}$, Phạm Trung Kiên ${ }^{2}$, Trần Tuấn Anh ${ }^{1}$,
} Ngô Thị Kim Quế ${ }^{1}$, Khổng Thị Ngọc Mai ${ }^{3}$

\section{TÓM TẮT}

Mục tiêu: Mô tả đăc điểm lâm sàng, xét nghiệm rối loạn đông máu ở trẻ sơ sinh nhiễm khuẩn huyết tại Trung tâm Nhi khoa, Bệnh viện Trung ương Thái Nguyên. Phương pháp nghiên cứu: nghiên cứu mô tả tiến cứu 38 bệnh nhẩn nhiễm khuẩn huyết tại Trung tâm Nhi khoa. Kết quả: triệu chứng của nhiễm khuấn huyết hay gặp là khó thở $86,8 \%$, bú kém $84,2 \%$, có $34,2 \%$ trẻ có biểu hiện xuất huyết dưới da, chảy máu phổi $10,6 \%$. Số lượng tiểu câuu giảm chiếm $55,3 \%$ trường hợp; tỉ lệ prothrombin giảm chiếm $44,7 \%$, thời gian Thromboplastin từng phần hoạt hoá (APTT) kéo dài chiếm 34,2\% và fibrinogen giảm chiếm 34,2\%. Kết luận: các biểu hiện lâm sàng của nhiễm khuẩn huyết ở trẻ sơ sinh hay găp là các dấu hiêu khó thở, bú kém. Các rối loạn đông cầm máu là giảm số lượng tiểu cầu, tỉ lê prothorombin giảm, APTT kéo dài.

Tư khóa: Rối loạn đông máu, nhiễm khuẩn huyết, sơ sinh, cây máu

\section{SUMMARY}

CLINICAL CHARACTERISTICS OF

COAGULATION DISORDERS OF NEONATAL

SEPSIS AT THAI NGUYEN NATIONAL HOSPITAL'S PEDIATRIC CENTER

Objectives: Description of clinical features and coagulation disorders in neonates infected by sepsis at Thai Nguyen National hospital's Pediatric center. Methods: across-sectional descriptive study. Results: Common clinical symptoms of sepsis are difficult breathing $86.8 \%$, poor feeding $84.2 \%$, mainly $34.2 \%$ of them are subcutaneous bleeding, followed by pulmonary bleeding with $10.6 \%$. The decrease in platelet count accounted for $55.3 \%$ of cases, the rate of Prothrombin decreased by $44.7 \%$, activated partial thromboplastin time (APTT) was prolonged by $34.2 \%$ and decreased fibrinogen accounted for $34.2 \%$. Conclusions: The most common clinical

${ }^{1}$ Trường Đại học Y-Dược, Đại học Thái Nguyên

${ }^{2}$ Trường Đại học Y Dược, Đại học Quốc gia Hà Nội

${ }^{3}$ Trường Đại học Đại Nam

Chiu trách nhiệm chính: Đỗ Thái Sơn

Email: dothaison@tnmc.edu.vn

Ngày nhận bài: 8.9.2021

Ngày phản biện khoa học: 25.10.2021

Ngày duyệt bài: 10.11.2021 manifestations of neonatal sepsis are difficulty breathing, and poor feeding. The coagulation disorders are decreased platelet count, decreased prothrombin ratio, extended APTT.

Keywords: coagulation, sepsis, neonates, blood culture.

\section{I. ĐẶT VẤN ĐỀ}

Nhiễm khuẩn huyết sơ sinh là nhiễm trùng toàn thân nặng, bệnh không chỉ gây tử vong hàng đâu ở cả trẻ sơ sinh đủ tháng và non tháng, mà còn để lại những di chứng nặng nê. Nhiễm trùng huyết là một biểu hiện đáp ứng của cơ thể với nhiễm trùng, gây ra hẩu hết các triệu chứng của nhiễm khuẩn huyết. Chẩn đoán sớm nhiễm khuẩn huyết ở trẻ sơ sinh không dễ dàng vì biểu hiện lâm sàng không đặc hiệu, các biểu hiện này rất đa dạng, tùy thuộc vào mức độ nghiêm trọng của nhiễm khuẩn huyết, nhanh chóng trở nên nặng nề,một trong những hậu quả là rối loạn đông máu và tổn thương các cớ quan. Bình thường hệ thống đông máu ở trạng thái cân bằng động, khi có tác động của nội độc tố, ngoại độc tố vi khuẩn vào hệ thống này thì đều có thể xẩy ra rối loạn đông máu, vì vậy rối loạn đông máu rất hay gặp ở trẻ sơ sinh nhiễm trùng huyết, các rối loạn này ở nhiều mức độ khác nhau từ nhẹ đến nặng, như đông máu nội quản rải rác, xuất huyết não. Tại Trung tâm Nhi khoa Bệnh viện Trung ương Thái Nguyên, hàng năm trẻ sơ sinh chiếm $23,5 \%$ số bệnh nhân vào viện điều trị, trong đó tỉ lệ trẻ nhiễm khuẩn huyết cao [4]. Vì vậy chúng tôi tiến hành nghiên này nhằm mục tiêu: Mô tả đặc điểm lâm sàng và xét nghiệm rôi loạn đông máu ở trẻ sơ sinh nhiễm khuẩn huyêt tại Trung tâm Nhi khoa Bệnh viện Trung ương Thái Nguyên.

II. ĐỐI TƯỢNG VÀ PHƯƠNG PHÁP NGHIÊN CỨU

2.1 Đối tượng nghiên cứu. Trẻ sơ sinh nhiễm khuẩn huyết điều trị tại Trung tâm Nhi khoa Bệnh viện Trung ương Thái Nguyên trong thời gian nghiên cứu. 